\title{
The effect of lameness on the resting behavior and metabolic status of dairy cattle during the transition period in a freestall-housed dairy herd
}

\author{
D. F. Calderon and N. B. Cook ${ }^{1}$ \\ School of Veterinary Medicine, University of Wisconsin-Madison 53706-1102
}

\begin{abstract}
The objective of this observational study was to examine the effect of lameness on the resting behavior of dairy cattle through the transition period in a mattress-bedded commercial freestall facility, and explore the relationships between lameness, behavior, and metabolic indicators of disease. A convenience sample was used, comprised of 40 multiparous and 17 primiparous Holstein cows that were recruited as they entered the close-up pen and tracked through the maternity, hospital, and fresh pens. At recruitment, $87.5 \%$ of multiparous cows and $23.5 \%$ of primiparous cows showed evidence of abnormal gait. Lying time decreased from $16 \mathrm{~d}$ before calving from a least squares means \pm standard error of $13.5 \pm 0.6 \mathrm{~h} / \mathrm{d}$ to a nadir of $10.6 \pm 0.38$ $\mathrm{h} / \mathrm{d}$ on the day of calving. After a period of increased rest after calving, lying time stabilized by d 6 to between 9.8 and $10.8 \mathrm{~h} / \mathrm{d}$. This change was accompanied by an increase in the number of lying bouts per day from least squares means (95\% confidence limits) of 11.2 (10.0 to 12.4) bouts per day to a peak of 17.7 (16.5 to 18.8) bouts per day on the day before calving, and a decrease in the duration of each lying bout. Resting behavior was influenced by calving month, temperature humidity index, body condition, parity, and lameness. Moderate and severely lame cows had significantly longer lying times throughout the transition period before and after calving, but most notable was a dramatic increase in the number of lying bouts observed $3 \mathrm{~d}$ before and after calving. In the straw-bedded, loose-housed maternity pen, moderate and severely lame cows had 20.3 (19.1 to 21.5 ) bouts per day, compared with 15.6 (14.3 to 16.8) bouts per day for nonlame cows. We hypothesized that this alteration in behavior may be associated with hypersensitivity to pain due to lameness. A total of $26.3 \%$ of cows tested above a threshold of 1,400 $\mu M \beta$-hydroxybutyrate. Moderate and severely lame cows had a least squares means (95\% confidence
\end{abstract}

Received September 23, 2010.

Accepted February 3, 2011.

${ }^{1}$ Corresponding author: nbcook@wisc.edu limits) $\beta$-hydroxybutyrate concentration of $1,165(1,037$ to 1,291$) \mu M$ that was significantly greater than 697 (560 to 834) $\mu M$ for slightly lame cows and 687 (551 to 824) $\mu M$ for nonlame cows. In summary, lameness significantly altered the resting behavior of cows during the transition period and was associated with elevated risk for ketosis in the study herd.

Key words: transition, lameness, behavior

\section{INTRODUCTION}

Recently, the eating and resting behavior of dairy cows during the critical transition period from $3 \mathrm{wk}$ before to $3 \mathrm{wk}$ after calving has been the focus of several studies (Huzzey et al., 2005; Huzzey et al., 2007; Proudfoot et al., 2009). Cows significantly decreased average daily lying time by $1.1 \mathrm{~h} / \mathrm{d}$ from the pre-fresh period $(11.7 \mathrm{~h} / \mathrm{d})$ to the post-fresh period $(10.6 \mathrm{~h} / \mathrm{d})$ in one study on 12 cows housed in a sand-bedded freestall facility (Huzzey et al., 2005). Average lying time decreased to $9.6 \mathrm{~h} / \mathrm{d}$ for the day immediately before and after calving, with a significant increase in the number of standing bouts ( 17.3 bouts/d).

Lameness prevention remains a significant priority for the dairy industry as consumer demand drives changes in housing and management to promote improved wellbeing, and farmers strive for improved productivity. Lameness prevalence appears to be greater in freestall facilities compared with other management systems such as tie-stall housing (Wells et al., 1993; Bergsten and Herlin, 1996; Sogstad et al., 2005). Exposure to concrete walking surfaces in alleys and other changes such as the regrouping of cattle around the time of calving are potential differences typical of freestall design and management that may be important factors elevating lameness risk (Cook and Nordlund, 2009). Approximately 20 to $25 \%$ of intensively managed dairy cattle in North America are lame at any one time (Cook, 2003; Espejo et al., 2006) and lameness is known to alter resting and feeding behavior (González et al., 2008; Gomez and Cook, 2010; Ito et al., 2010). Given that a large proportion of these cattle must transition from the current lactation to the next, and that the risk for lameness persists across lactations (Hirst et al., 2002), 
surprisingly little research exists describing the effect of lameness on transition cow behavior and health. Lame cows were not included in any of the transition cow behavior studies conducted recently (Huzzey et al., 2005; Huzzey et al., 2007; Chapinal et al., 2009; Proudfoot et al., 2009; Proudfoot et al., 2010), and all of these studies used a facility with sand bedding, which is known to alter resting behavior compared with stalls with mattress beds, by increasing the duration of lying bouts and decreasing the number of bouts per day (Cook et al., 2004; Gomez and Cook, 2010).

The shift in the pattern of resting behavior observed as cows transition may have consequences for the risk of lameness onset in early lactation. Periparturient cattle undergo non-inflammatory changes in the connective tissue of the corium of the foot that impair their resilience to external stresses at this critical time (Webster, 2001; Knott et al., 2007). Any decline in rest may contribute to the loading stress the hoof is exposed to, and exacerbate the severity of the lesion that subsequently develops. Indeed, Chapinal et al. (2009) have recently shown that nonlame cows that went on to develop a sole ulcer in early lactation suffered a faster decrease in lying time before calving and a faster increase afterward, compared with cows that did not develop a lesion, when housed in sand-bedded freestalls, and Proudfoot et al. (2010) have also shown that cows diagnosed with claw horn lesions in midlactation spent longer standing 2 wk before calving and $24 \mathrm{~h}$ after calving than cows without lesions in a similar facility.

The aims of this observational study were to monitor the resting behavior of multiparous and primiparous cows through the transition period in a commercial dairy herd with a naturally occurring high prevalence of lameness, housed in a mattress-bedded freestall facility, and to explore the relationships between lameness, periparturient behavior, and metabolic indicators of disease.

\section{MATERIALS AND METHODS}

\section{Herd Management and Cow Selection}

A total of 57 Holstein dairy cattle were recruited from a pool of cows calving between June 12 and November 2, 2007 on an 834-cow commercial Holstein dairy herd located in South Central Wisconsin. The herd was housed in a naturally ventilated freestall barn and lactating cows were parlor milked 3 times daily. Rolling herd average milk production was $13,220 \mathrm{~kg}$. Cows were fed a TMR diet once per day, delivered between 0900 and $1100 \mathrm{~h}$, formulated to meet the requirements for dry and lactating dairy cows (NRC, 2001). Transition period management consisted of a 53-d average dry pe- riod with a combination of freestall (far-dry, close-up, hospital, and fresh cow pens) and loose housing with deep straw bedding (maternity pen). Cows were moved from the far-dry group to the close-up group approximately $21 \mathrm{~d}$ before expected due date. Periparturient cows were moved from the close-up freestall pen to the maternity pen area typically $4 \mathrm{~d}$ before calving and immediately postpartum all cows were milked and moved to a hospital pen for approximately $8 \mathrm{~d}$, before being moved to a fresh cow pen.

All freestall pens were similarly designed with 1.17-m-wide stalls fitted with new combination foam and rubber crumb-filled mattresses (Premium Pad Pasture Mat; Promat Ltd., Ontario, CA) in a 2-row head-to-head layout, bedded with a small amount of sawdust 3 times per week. The feed-line of all pens was fitted with headlocks located $0.60 \mathrm{~m}$ on center, with a water soaker system activated at $24^{\circ} \mathrm{C}$ for heat abatement during the summer. Recirculating fans were located over the stalls in all pens.

At 3 locations in the barn (the maternity pen area and the north and south end of the transition cow freestall barn), temperature and humidity were recorded using data loggers (Dickson TR320 Pro Series; Dickson, Addison, IL). The data were downloaded for each minute of each day and the temperature-humidity index (THI) determined using the equation $\mathrm{THI}=\mathrm{T}-(0.55-0.55$ $\times \mathrm{RH}) \times(\mathrm{T}-58)$, where $\mathrm{T}$ is the ambient temperature in ${ }^{\circ} \mathrm{F}$, and $\mathrm{RH}$ is the relative humidity expressed as a decimal (NOAA, 1976). The mean THI was determined for each cow stay in each pen using data from the nearest datalogger.

\section{Data Collection and Sampling}

Study cows were recruited systematically from a convenience sample of cows recently moved from the far-dry to the close-up group each week as the cows were moved through a trimming chute based on the availability of activity monitors. Each cow received a BCS using a 5-point scale (Edmonson et al., 1989), a locomotion score (LMS) on level concrete using a 4-point scale described by Nordlund et al. (2004), and all 4 feet were trimmed on the day of recruitment. For analysis, BCS was categorized as thin $(<3.0)$, moderate (3.0-3.75), and fat $(\geq 4.0)$ and LMS was collapsed down into 3 scores where score $1=$ nonlame, score 2 $=$ slightly lame, and score $3=$ moderate and severely lame. Cows were locomotion scored every 2 to 3 wk up to 110 DIM and any cows increasing in severity were submitted for treatment by the hoof trimmer and the foot and lesion recorded. The LMS were classified into 5 assessment periods from recruitment (LMS1) to the final score (LMS5) by 110 DIM. 
Digital pictures were taken of each foot and lesions scored to classify claw health of the cow at recruitment, according to the scheme recommended by Shearer et al. (2004), as normal ( $\mathbf{n}=$ no significant lesion), hemorrhage $(\mathbf{H}=$ presence of hemorrhage in the sole or white line of at least one foot), claw lesion $(\mathbf{C}=$ presence of a full thickness sole defect or ulcer in the typical site or a white line fissure or abscess), and infectious lesion ( $\mathbf{I}=$ presence of interdigital phlegmon or digital dermatitis).

For measurement of lying behavior, 15 automatic activity monitors (IceTag, IceRobotics, Roslin, UK) were rotated between cows. The monitor was attached to the left rear limb of each cow with a Velcro strap and Vet-Wrap (Co-Flex, Andover Coated Products Inc., Salisbury, MA) and left on for the duration of the transition period up to $16 \mathrm{~d}$ after calving. Once data had been downloaded, the IceTag was cleaned, reactivated, and placed on the next cow recruited. IceTag availability was, therefore, the limiting factor determining the number of cows that could be recruited each week.

One of the authors (D. F. Calderon) visited the farm every 2 to $3 \mathrm{~d}$ for the duration of the project. Using data stored in DairyComp305 (Valley Agricultural Software, Tulare, CA) and information from the herdsman, the precise time and date of calving and the date of any pen movement of the study cows was recorded. At each visit, each transition cow pen was examined and data collected. For each pen, feed bunk length, number of stalls, and number of cows were counted to calculate bunk space per cow and stall stocking density (number of cows in the pen divided by the number of stalls in the pen that day). These data were used to calculate the average stocking density (cows per stall) and bunk space ( $m$ per cow) experienced by each cow for the duration of each pen stay. Calving ease was scored by the farm and defined as $0=$ no assistance or gentle manual pull or $1=$ assistance using ropes/chains or harder. Calving ease score 1 was considered a dystocia.

As a measure of fat mobilization before calving, a measurement of blood NEFA concentration was captured within the period 2 to $10 \mathrm{~d}$ before calving. Study cows in the close-up pen and maternity pen were individually locked up in the stanchions at the feed bunk and bled from a coccygeal vessel at each visit into heparinized tubes and the tubes were immediately placed on ice. Plasma was separated by centrifuge at $2,500 \times g$ for $10 \mathrm{~min}$ and held frozen until each cow had calved. The last sample in the target sample window was submitted to a commercial laboratory (Marshfield Clinic Veterinary Diagnostic Services, Marshfield, WI) for analysis of NEFA using the Wako NEFA-C test kit (Wako Chemicals USA Inc., Richmond, VA).

As a measure of ketosis, at least 2 measurements of BHBA before $16 \mathrm{~d}$ after calving were captured. Study cows in the hospital pen and fresh pen were bled once per week from a coccygeal vessel into tubes without additive and the blood was allowed to clot. Tubes were centrifuged on-farm at $2,500 \times g$ for $10 \mathrm{~min}$ to separate the serum, which was frozen until the sample was analyzed by Marshfield Clinic Veterinary Diagnostic Services using a Roche-Hitachi automated analyzer (Stanbio Laboratory, Boerne, TX) and module P enzymatic quantification method. The DIM and test value for the highest $\mathrm{BHBA}$ concentration obtained (BHBA $_{\max }$ ) were recorded. To minimize social disruption, the sampling was performed during the normal daily lock up period for fresh cow health checks, using the stanchions over the feed bunk.

\section{Activity Data}

Use of IceTag activity monitors has been previously reported (Munksgaard et al., 2006; Endres and Barberg, 2007; Bewley et al., 2010). Each unit uses an accelerometer to automatically determine the percentage of each minute spent standing, lying, and active. Data from each cow were downloaded into a .csv file that was then read into an Access database (Microsoft Corp., Redmond, WA). Queries were run to calculate the number of lying bouts, mean lying bout duration, and total lying time for each 24 -h period before and after calving. For all behaviors, the 24 -h period after calving was adjusted so that the first hour of this period was the precise hour of calving. All other days were recorded midnight to midnight. A lying bout was defined as a period following standing activity where $\geq 50 \%$ of the recorded activity was lying for at least 2 consecutive minutes (Munksgaard et al., 2006). This algorithm was checked against video surveillance for a selection of the dataloggers before and after the study using cows in a tie-stall and found to give good agreement. Due to variation in the actual time of calving, daily data were available for up to $16 \mathrm{~d}$ before calving and up to $16 \mathrm{~d}$ after calving. Only cows with a minimum of $6 \mathrm{~d}$ of data before calving were retained in the activity analysis (n $=52)$.

\section{Statistical Analyses}

Statistical analyses were performed in SAS (version 9.2; SAS Institute, 2009) using cow as the experimental unit. The distribution of resting time variables: lying time, number of lying bouts per day, and mean lying bout duration, along with NEFA and $\mathrm{BHBA}_{\max }$ concentrations were screened for normality using the PROC UNIVARIATE procedure and all but lying time were log-transformed to ensure an approximate normal distribution of residuals plotted against predicted values. 
The ANOVA procedure was used to compare mean LMS1 score by hoof lesion category (N, I, H, and C) and for comparison of LMS between assessment periods (LMS1-5) for primiparous and multiparous cows. In addition, PROC FREQ was used to perform the McNemar test to compare transitions between an LMS of 1 and score $\geq 1$ between each LMS assessment period.

Separate models were formulated for the metabolic outcomes NEFA concentration and $\mathrm{BHBA}_{\max }$ using PROC MIXED in SAS and manual stepwise backward elimination of nonsignificant $(P>0.05)$ effects. Fixed effects considered for each model included parity, LMS1, BCS, calving month, calving ease score, and pen-appropriate measures (close-up pen for NEFA and hospital pen for $\mathrm{BHBA}_{\max }$ ) of stocking density, bunk space, duration of pen stay, and THI.

A time-only analysis for the resting behaviors: time lying, number of lying bouts per day, and mean lying bout duration was performed in PROC MIXED from d -16 to $\mathrm{d}+16$ after calving, using a repeated measures model with cow as the repeated subject. Both autoregressive and compound symmetry covariance structures were tested and the model with the lower Akaike Information Criterion retained. For all models, the autoregressive structure was favored. In addition to the effect of day relative to calving, other covariates considered included class variables: parity $(1,2$, or $\geq 3)$, calving month (June-November), BCS, calving ease score, and LMS1, and continuous variables: stocking density, bunk space, and THI for close-up, maternity, and hospital pens. Manual stepwise backward elimination of nonsignificant $(P>0.05)$ fixed effects was used and from the resultant models, plausible 2-way interactions were examined and retained if $P<0.05$. Differences in least squares means activities were tested using the Fisher protected least significant difference test. Where back transformed least squares means are reported, 95\% confidence limits are provided.

Pen-dependent repeated measures analyses were similarly performed for each resting behavior by day relative to calving for close-up, maternity, hospital, and fresh pens using pen-appropriate covariates for each analysis.

\section{RESULTS}

\section{Cow Recruitment and Management}

Fifty-seven cows (17 primiparous and 40 multiparous) were enrolled in the study with a median (range) parity of 2.0 (1 to 6) and a median (range) BCS of 3.75 (2 to 4.25). Between 6 and 16 cows were recruited per month from June to October, with 1 cow recruited in November. Mean \pm standard deviation THI for the close-up period was $67.6 \pm 4.5,67.4 \pm 6.2$ for the maternity period, and $66.2 \pm 7.6$ for the fresh period, with a range across all days from 45.7 to 75.6. Dystocia was recorded for $41 \%$ of primiparous cows and $27.5 \%$ of multiparous cows.

\section{Hoof Lesions and Lameness}

Changes in LMS were observed for primiparous cows relative to assessment period. These transitions are shown in Figure 1. Mean \pm standard deviation days relative to calving for each of the 5 LMS assessment periods (LMS1-5) were $-16.4 \pm 7.8,16.1 \pm 9.4,37.4$ $\pm 11.2,60.3 \pm 11.7$, and $88.6 \pm 12.1 \mathrm{~d}$. At LMS1 on $\mathrm{d}$ $-16,35$ of the $40(87.5 \%)$ multiparous cows scored 2 or greater compared with 4 of the $17(23.5 \%)$ primiparous cows. Although no significant changes in LMS were observed throughout the survey period in the multiparous group, changes in LMS were noted for primiparous cows in early lactation. In the transition from LMS2 to LMS3, $52.9 \%$ of heifers scored 2 or greater at 37 DIM compared with $29.4 \%$ at 16 DIM $(P<0.05)$, shown in Figure 1.

At the dry period trim, 15 cows had no significant lesion (N), 7 cows were identified with an infectious lesion (I), 22 cows had sole or white line hemorrhage $(\mathrm{H})$, and 13 cows were affected by an ulcer or white line abscess $(\mathrm{C})$. Mean \pm standard deviation locomotion scores at the dry period trim (LMS1), corresponding to the lesion categories $\mathrm{N}, \mathrm{I}, \mathrm{H}$, and $\mathrm{C}$, were $1.93 \pm 0.80$, $1.86 \pm 0.90,1.68 \pm 0.72$, and $3.0 \pm 0.0$, respectively. Differences between lesion $\mathrm{C}$ and all other categories were significant at $P<0.05$.

Of the 18 score 1 cows at LMS1 ( 5 multiparous and 13 primiparous cows), 4 cows transitioned to an LMS of 3 during the period of study. For 3 of the 4 cows, a $\mathrm{C}$ lesion was identified on at least one foot.

\section{Metabolic Status}

Mean (standard deviation) time of collection of blood for NEFA evaluation before calving was $-5.0 \pm 2.1 \mathrm{~d}$, with a range from -2 to $-10 \mathrm{~d}$. One study cow calved before blood sampling. Mean NEFA concentration was 230 (210) $\mu M$, with 8 out of 56 cows sampled testing at or greater than the threshold of $400 \mu M$ concentration used by Oetzel (2004) to indicate an elevated risk for prepartum negative energy balance and fatty liver. Despite NEFA being a significant risk factor for ketosis, none of the cows with NEFA greater than the $400 \mu M$ cut-point before calving went on to develop $\mathrm{BHBA}_{\max }$ greater than the 1,400 $\mu M$ cut-point used to define sub- 
$\mathbf{m}_{1} \square_{2} \nabla_{3}$

Primiparous

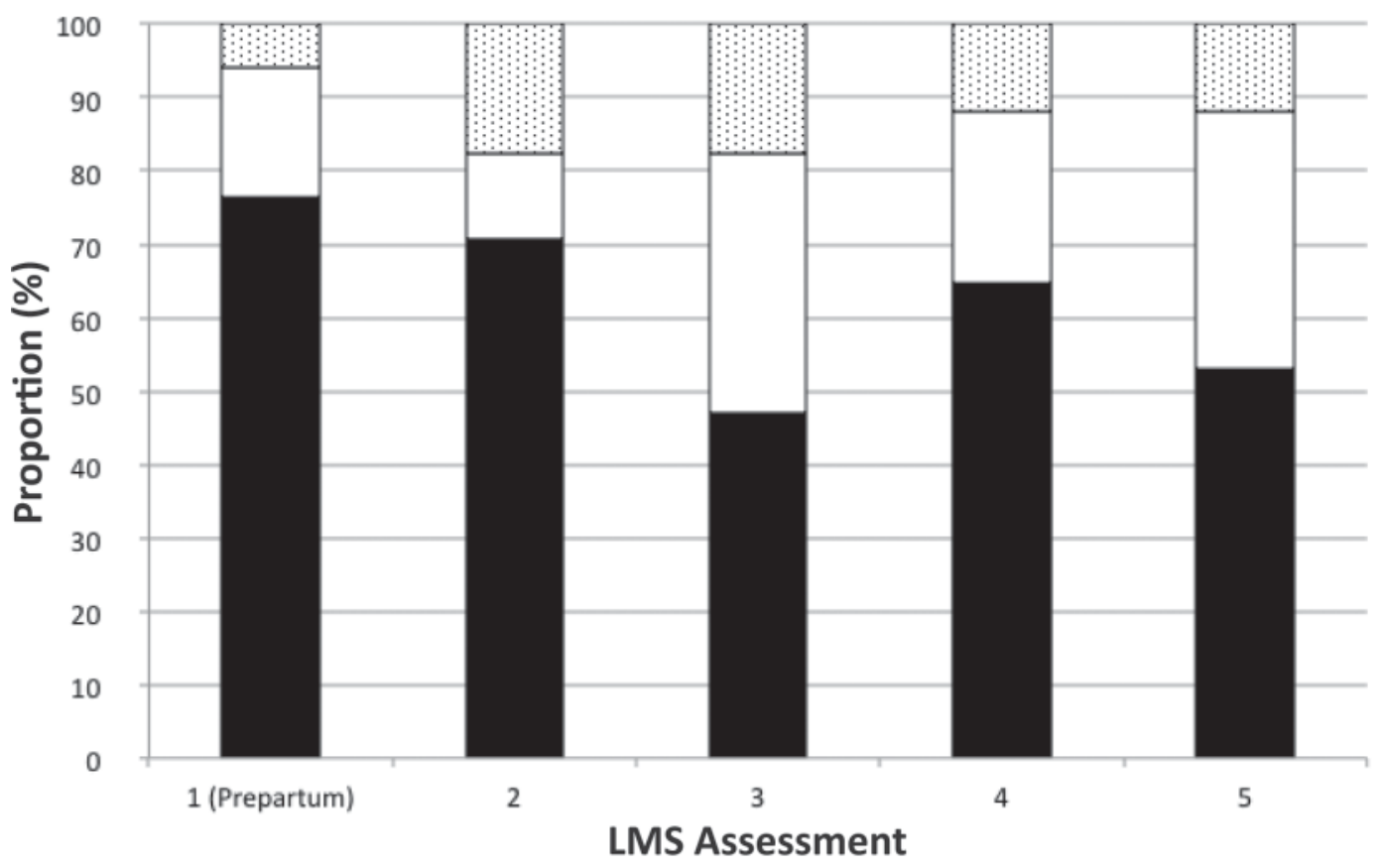

Multiparous

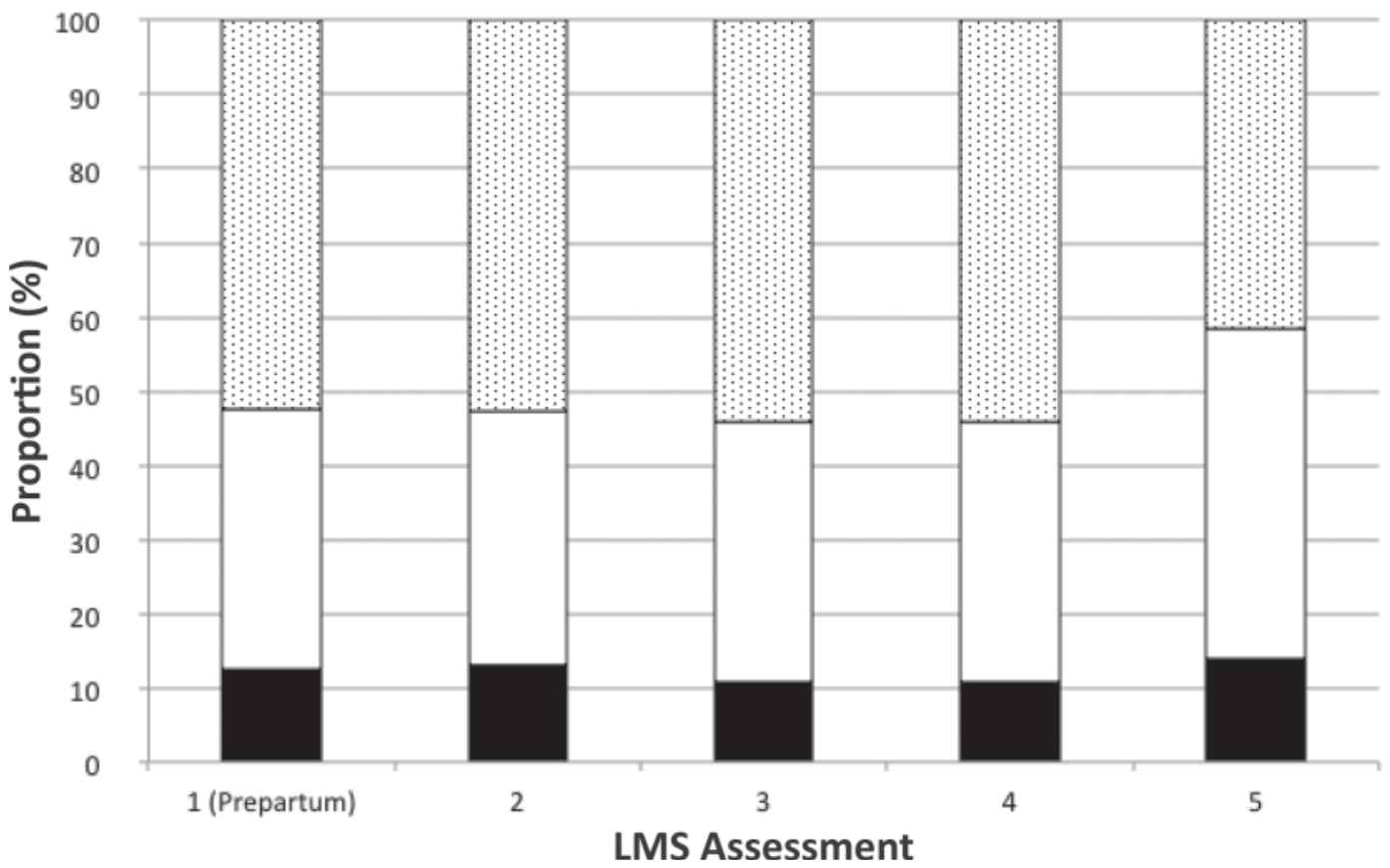

Figure 1. Proportion of primiparous $(\mathrm{n}=17)$ and multiparous $(\mathrm{n}=40)$ cows at each locomotion score (LMS; $1=$ normal, $2=$ slightly lame, $3=$ moderately or severely lame) for 5 locomotion score assessment periods (LMS1-5), where mean days relative to calving for each score period were $1=-16$ (prepartum), $2=16,3=37,4=60$, and $5=89 \mathrm{~d}$. 
Table 1. Estimate and standard error for the model for $\mathrm{BHBA}_{\max }{ }^{1}$ with $F$-value and $P$-value for type III test of fixed effects

\begin{tabular}{lcccc}
\hline Parameter $^{2}$ & Estimate & $\mathrm{SE}$ & $F$-value & $P$-value \\
\hline Intercept & 4.17 & 0.90 & & \\
THI & -0.03 & 0.01 & 7.64 & $<0.01$ \\
BCS & 0.81 & 0.37 & 2.95 & $<0.05$ \\
Fat & 0.58 & 0.36 & & \\
Moderate & ref & & & \\
Thin & & & & \\
LMS1 & -0.53 & 0.18 & 5.76 & $<0.01$ \\
Score 1 & -0.51 & 0.18 & & \\
Score 2 & ref & & & \\
Score 3 &
\end{tabular}

${ }^{1}$ The highest BHBA concentration obtained.

${ }^{2} \mathrm{THI}=$ mean temperature humidity index experienced in the hospital pen; $\mathrm{BCS}=$ body condition score at recruitment; LMS1 = locomotion score at assessment 1 at mean of $-16.4 \mathrm{~d}$ before calving; score $1=$ nonlame, score $2=$ slightly lame, and score $3=$ moderate and severely lame.

clinical ketosis (Oetzel, 2004; Duffield et al., 2009). No predictor variables tested were found to be associated with the outcome of NEFA concentration.

Mean (standard deviation) time of collection of $\mathrm{BHBA}_{\max }$ was $9.2 \pm 3.9 \mathrm{~d}$ after calving, with a range from 3 to $17 \mathrm{~d}$. Mean $\mathrm{BHBA}_{\max }$ concentration was 1,260 (850) $\mu M$ with 15 out of 57 cows (26.3\%) testing at or greater than the threshold of $1,400 \mu M$ used to define subclinical ketosis (Oetzel, 2004; Duffield et al., 2009).
The model developed for $\mathrm{BHBA}_{\max }$ is summarized in Table 1. The THI average for the hospital pen was negatively associated with $\mathrm{BHBA}_{\max }$. The fat cows had a higher BHBA $_{\max }$ concentration compared with thin cows and a significant effect was present for LMS1 $(P<$ 0.01). The BHBA $A_{\max }$ was significantly higher for LMS1 score 3 cows than for score 1 cows $(P<0.01)$ and score 2 cows $(P<0.01)$, with a least squares means $(95 \%$ confidence limits) $\mathrm{BHBA}_{\max }$ of 1,165 (1,037 to 1,291) $\mu M$ compared with 687 (551 to 824$) \mu M$ for score 1 and 697 (560 to 834) $\mu M$ for score 2.

\section{Time-Only Analysis}

Least squares means by day for 3 final models for lying time, number of lying bouts per day, and mean lying bout duration from $16 \mathrm{~d}$ before to $16 \mathrm{~d}$ after calving are shown in Figure 2.

Significant fixed effects for lying time included day $(P<0.01)$, calving month $(P=0.03)$, and LMS1 $(P<$ $0.01)$, with no significant interactions. Lying time decreased by approximately $3 \mathrm{~h}$ from $\mathrm{d}-16$ to a nadir on d 1 from least squares means \pm standard error of 13.5 $\pm 0.6 \mathrm{~h} / \mathrm{d}$ to a nadir of $10.6 \pm 0.38 \mathrm{~h} / \mathrm{d}$. After calving, a brief recovery occurred with lying times exceeding $11 \mathrm{~h} / \mathrm{d}$ until d 6; then, resting behavior appeared to

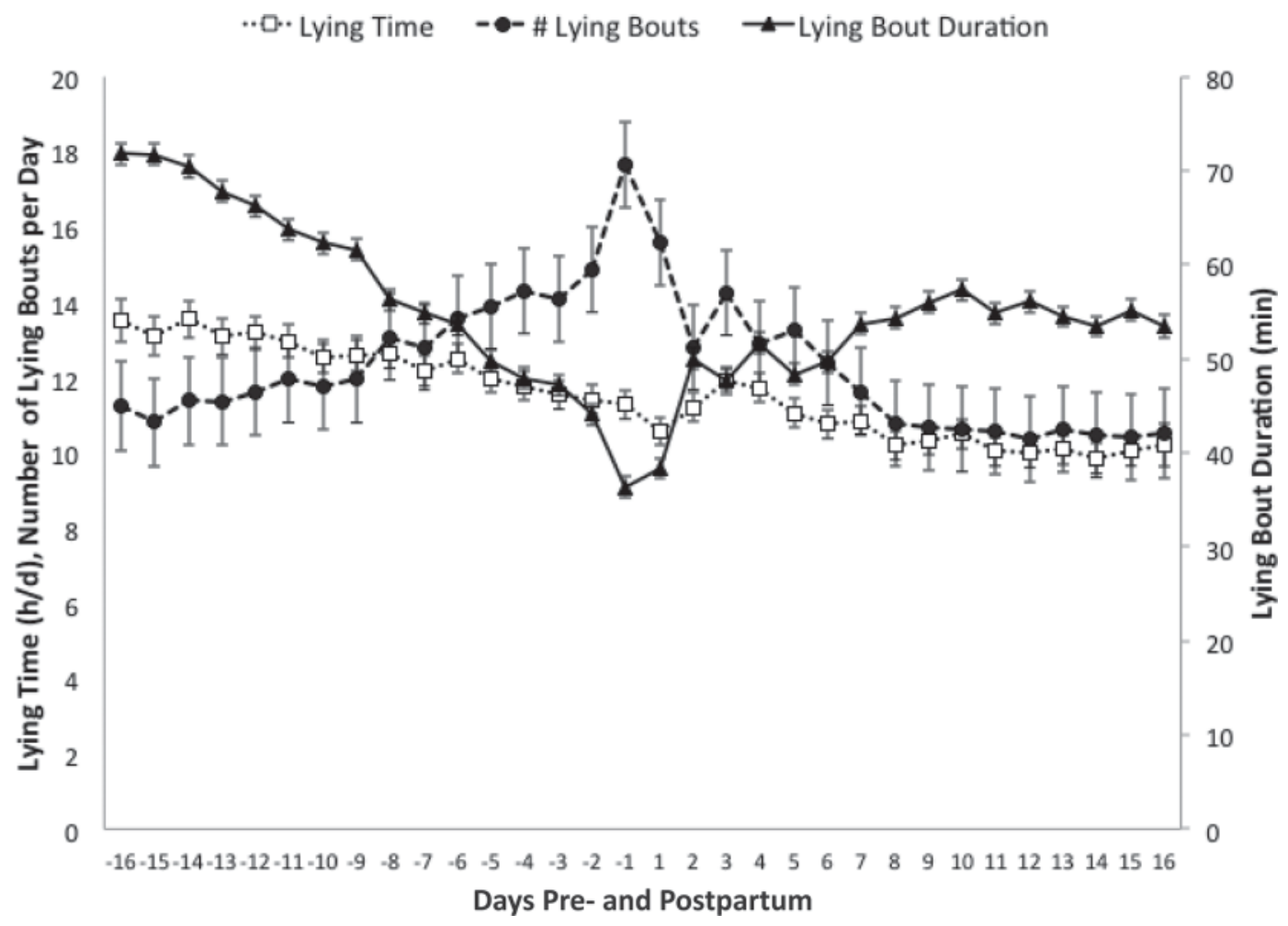

Figure 2. Changes in least squares means of lying time (h/d), number of lying bouts per day, and mean lying bout duration (min) from the final repeated measures models from $\mathrm{d}-16$ to 16 after calving, with standard error bars. 
stabilize between 9.8 and $10.8 \mathrm{~h} / \mathrm{d}$. Lying time was significantly longer for cows calving in October compared with those calving in June and July $(P<0.05)$. The effect of LMS1 on resting behavior during the transition period is shown in Figure 3. Score 3 cows had significantly longer lying times throughout the period of study than score 1 and score 2 cows $(P<0.01)$.

Significant changes in number of lying bouts were observed with day $(P<0.01)$, BCS $(P<0.01)$, and LMS1 $(P<0.01)$ in the final model. Least squares means of number of bouts (95\% confidence limits) increased from 11.2 (10.0 to 12.4 ) to a peak of 17.7 (16.5 to 18.8 ) bouts per day on $\mathrm{d}-1$, followed by stabilization to approximately 10.5 bouts/d by d 8 after calving (Figure 2). The thin cows had significantly fewer bouts than did moderate or fat cows $(P<0.05)$ and the effect of LMS1 was most pronounced for $3 \mathrm{~d}$ before and after calving, where score 3 cows had a significantly elevated number of bouts compared with score 1 and 2 cows (Figure 3 ).

For mean lying bout duration, the effect of day was significant $(P<0.01)$ along with BCS $(P<0.01)$ and LMS1 $(P<0.01)$. The effect of day is shown in Figure 2 with a decrease in least squares means (95\% confidence limits) of mean lying bout duration from 71.8 (70.6 to 73.0) min per bout to a nadir of 36.3 (35.2 to 37.5$) \mathrm{min}$ per bout at $\mathrm{d}-1$. Lying bout duration stabilized around d 7 after calving. The thin cows had significantly longer bout durations than did moderate or fat cows $(P<0.05)$ and the effect of LMS1 is shown in Figure 3, where score 2 cows had significantly longer durations than score 1 or score 3 cows $(P<0.05)$. On $\mathrm{d}-1$, the score 3 cows had the shortest lying bout duration.

\section{Pen-Dependent Analysis}

Cows spent a mean \pm standard deviation of $24.5 \pm$ $12.3 \mathrm{~d}$ in the close-up pen, $4.3 \pm 3.9 \mathrm{~d}$ in the maternity pen, and $8.1 \pm 6.9 \mathrm{~d}$ in the hospital pen before being moved to a fresh pen. Mean daily bunk space, stocking density, and THI experienced by the cows in each pen are summarized in Table 2.

Least squares means of lying time, number of lying bouts per day, and mean lying bout duration by LMS for each of the pen models are presented in Table 3 . In the final models for lying time, the effect of LMS was significant at $P<0.01$ for all pens. For the close-up group, a significant interaction existed between day and parity $(P=0.04)$, with lying time increasing as calving time approached from a nadir on $\mathrm{d}-5$ in primiparous cows, compared with a steady decrease in lying time in multiparous cows. For the fresh group, THI had a significant negative effect on lying time $(P=0.02)$. In all models, the effect of day alone was not significant.
For the number of lying bouts per day, LMS was also significant in all models at $P<0.05$, except for the close-up pen, where $P=0.07$. Parity alone was significant for the close-up model, where the number of lying bouts for primiparous cows was significantly greater than for multiparous cows (LSM $=16.51 ; 95 \%$ $\mathrm{CI}=15.31$ to 17.70 for primiparous vs. $\mathrm{LSM}=12.96$; $\mathrm{CI}=11.85$ to 14.06 multiparous; $P=0.04$ ). Day was a significant effect for the hospital and fresh pen models at $P<0.01$.

For mean lying bout duration, the effect of LMS was only significant for the close-up pen model $(P<0.01)$ where score 1 cows had shorter durations than either score 2 or score 3 cows. The effect of day was significant for the close-up and hospital pen models.

Across pen models, lying time was significantly greater for LMS 3 cows than for score 1 cows, and this increase was consistently associated with an increase in the number of lying bouts per day. This was especially marked in the maternity pen where LMS1 score 3 cows had over 20 lying bouts per day. The influence of LMS on mean lying bout duration was less clear, where for most models, score 2 cows had longer durations than either score 3 or score 1 cows.

\section{DISCUSSION}

Significant alterations in resting behavior were observed before and after calving in cows housed in a commercial dairy facility using a straw-bedded pack for the maternity period and mattress-bedded freestalls before and after calving.

Prior to calving, lying time decreased by approximately $3 \mathrm{~h} / \mathrm{d}$ with the nadir of $10.6 \mathrm{~h} / \mathrm{d}$ occurring on the day immediately following calving. The number of lying bouts per day increased before calving to a peak at $\mathrm{d}-1$ of 17.7 bouts, and concomitantly, the duration of each bout decreased. These findings are comparable to the nadir of $9.6 \mathrm{~h} / \mathrm{d}$ lying time described for 12 cows by Huzzey et al. (2005). That study did not report the number of lying bouts, but focused instead on standing bouts, with a peak around calving of 17.3 standing bouts per day. That study also used sand-bedded stalls and this type of stall surface is associated with fewer lying bouts of longer duration than mattress stalls (Gomez and Cook, 2010). However, given the similar change in behavior observed in the current study in a herd using mattress rather than sand freestalls, the findings suggest that these behavioral alterations are somewhat independent of the type of environment in which the cows are housed and may be considered a normal part of the process of parturition. Calving month significantly influenced time lying, with greater 

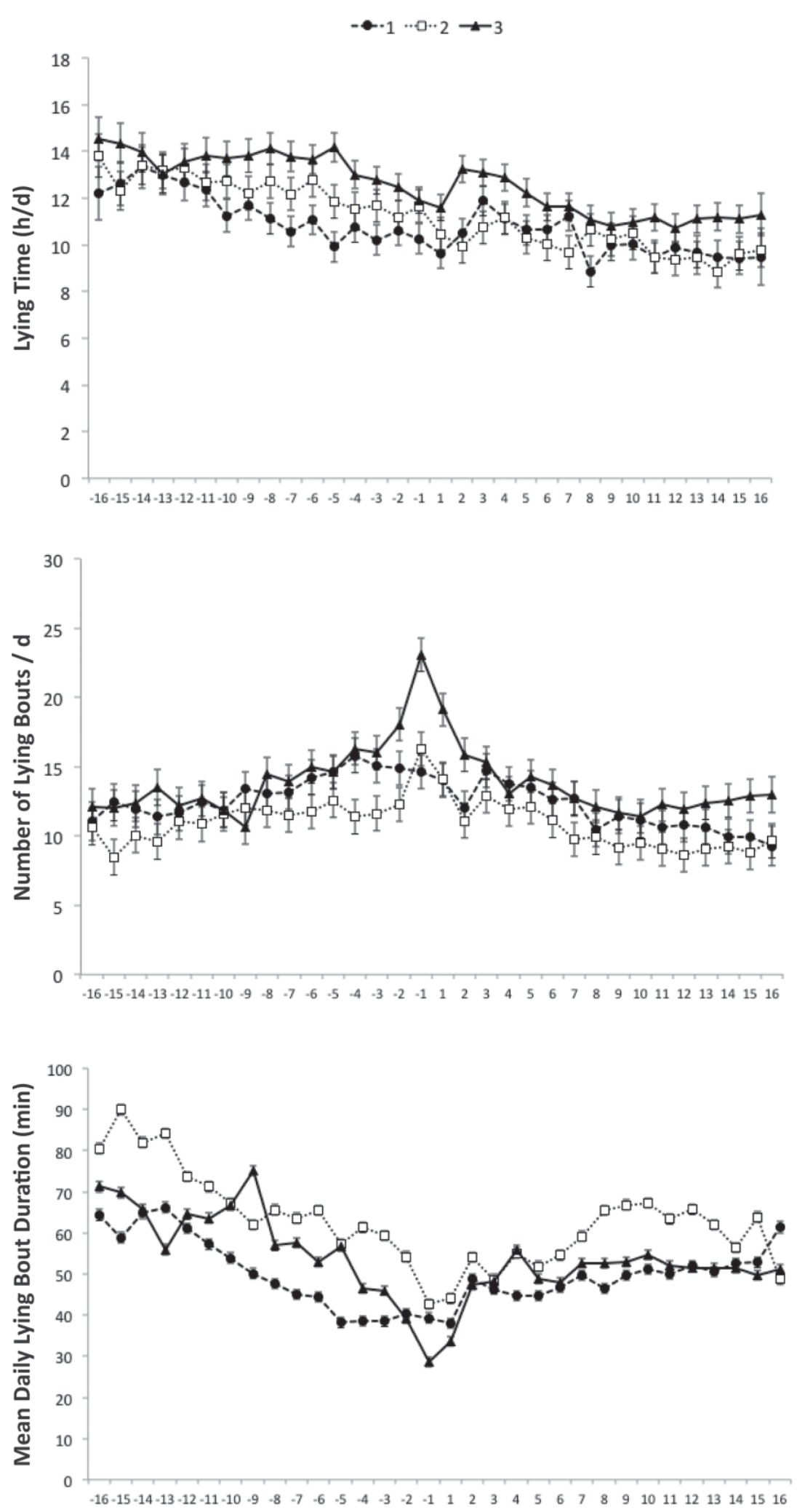

Days Pre- and Postpartum

Figure 3. The effect of locomotion score (LMS; $1=$ nonlame, $2=$ slightly lame, and $3=$ moderately or severely lame) on resting behavior (lying time, number of lying bouts per day, and mean lying bout duration) from d -16 to 16 after calving. Least squares means with standard error bars are shown from each of the final repeated measures models. 
Table 2. Mean \pm SD days in pen, bunk space per cow, stocking density, and temperature humidity index (THI) experienced by each cow for the duration of each pen stay

\begin{tabular}{lcccc}
\hline Pen & $\begin{array}{c}\text { Days in } \\
\text { pen }\end{array}$ & $\begin{array}{c}\text { Bunk space } \\
\text { per cow } \\
\text { (m/cow) }\end{array}$ & $\begin{array}{c}\text { Stocking } \\
\text { density } \\
\text { (no. of cows/stall) }\end{array}$ & THI \\
\hline Close-up & $24.5 \pm 12.3$ & $0.65 \pm 0.06$ & $0.95 \pm 0.09$ & $67.6 \pm 4.5$ \\
Maternity & $4.3 \pm 3.9$ & $0.99 \pm 0.23$ & $8.32 \pm 1.81^{1}$ & $67.4 \pm 6.2$ \\
Hospital $^{2}$ & $8.1 \pm 7.0$ & $0.70 \pm 0.17$ & $0.97 \pm 1.23$ & $66.2 \pm 7.6$ \\
Fresh $^{2}$ & $\mathrm{NR}$ & $0.57 \pm 0.10$ & $1.11 \pm 0.14$ & $\mathrm{NR}$ \\
\hline
\end{tabular}

${ }^{1}$ For the maternity pen, stocking density was measured in $\mathrm{m}^{2} /$ cow.

${ }^{2}$ For the fresh pen, duration of stay and mean THI were not recorded (NR).

times observed during October compared with the summer months. This observation was probably related to heat stress behavior as this is known to decrease lying times (Cook et al., 2007; Endres and Barburg, 2007).

Other factors that have been previously associated with altered behavior around the time of parturition are parity and dystocia. However, the results are equivocal. For example, Found et al. (2007) determined that heifers requiring assistance at delivery lay down longer than cows requiring assistance within $24 \mathrm{~h}$ of calving, whereas Proudfoot et al. (2009) found that cows with dystocia exhibited a greater number of lying bouts within $24 \mathrm{~h}$ of calving, with no change in resting time. In the current study, we identified a significant parity by day interaction during the close-up period for lying time and a parity effect for the number of lying bouts. Within the period 5 to $2 \mathrm{~d}$ before calving in the close-up freestall pen, lying time increased for primiparous cows compared with multiparous cows, and this change was associated with a significant increase in the number of lying bouts per day. The primiparous cows in this study suffered a 1.5 times greater rate of dystocia than the multiparous cows, but calving ease score was not significant in any of the close-up or maternity pen models. However, the calving ease score used was rather crude compared with the study by Proudfoot et al. (2009), and parturition was not observed by the researchers. Therefore, it is possible that the parity effect observed may be related to dystocia. Also, lameness was not accounted for in the prior studies and the interactions between parity, dystocia, and lameness are complex and difficult to separate out of observational data, but are worthy of further study.

Table 3. Least squares means (95\% CI in parentheses) of resting behavior (lying time, number of lying bouts per day, and mean lying bout duration) by locomotion score (LMS; 1 = nonlame, 2 = slightly lame, and $3=$ moderately or severely lame) for each transition pen model

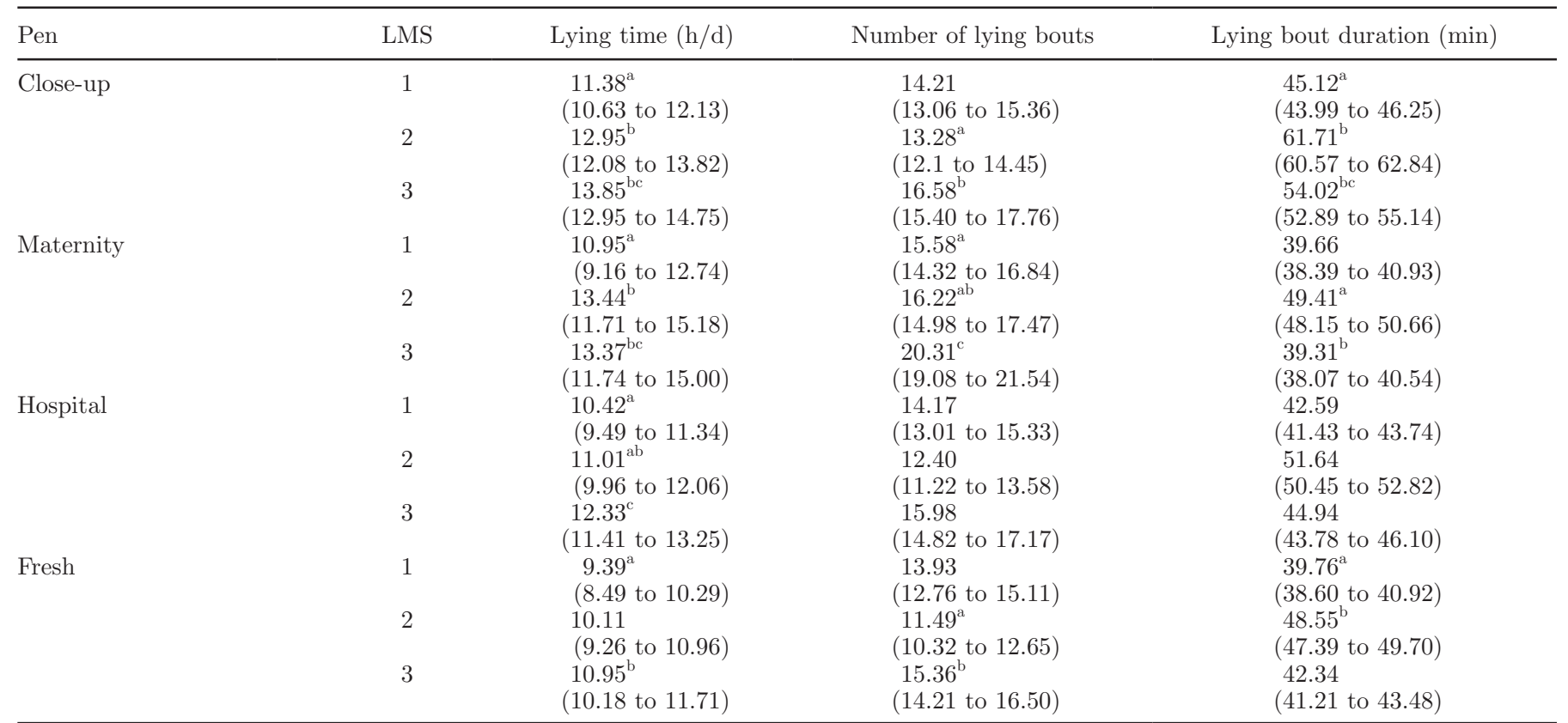

\footnotetext{
${ }^{\mathrm{a}, \mathrm{b}}$ Means within a column with different superscripts within each pen are significantly different at $P<0.05$ using Fisher's least significant dif-
} ference. 
The herd in this study was chosen for its high prevalence of lameness and $87.5 \%$ of multiparous and $23.5 \%$ of primiparous cows suffered an abnormal gait at recruitment before calving. Previous studies documenting behavior during the transition period have either not reported lameness as a covariate (Huzzey et al., 2005) or deliberately recruited only nonlame cows (Chapinal et al., 2009). The LMS 3 cows had significantly greater lying times throughout the period of study compared with score 1 and 2 cows, which was associated with a greater number of lying bouts, rather than any consistent effect on mean lying bout duration.

Whether or not lame cows rest for longer than nonlame cows is equivocal in the literature, with some studies claiming longer resting times (Ito et al., 2010) and some shorter (Chaplin et al., 2000; Cook et al., 2004; Cook et al., 2008). These studies were performed in lactating dairy cows and very little work has been published monitoring lame cow behavior during the nonlactating period. Gomez and Cook (2010) have shown that time milking may influence the time available for lying, especially for lame cows, and uninterrupted time in the pen may allow nonlactating lame cows to lie down for longer. However, even in the hospital and fresh pen, lying times were greater for LMS 3 cows, in a situation where the cows were milked 3 times per day. Stall surface type is known to alter stall use behavior (Gomez and Cook, 2010; Ito et al., 2010) and one disadvantage of the dataloggers in the current study was the failure to appreciate time spent standing in the stall each day. Greater time spent standing in the stall would also influence the time available for lying and appears to be the primary behavior change for lame cows in mattress stalls (Cook et al., 2008). The greater cushion of the foam/rubber combination mattress used in this study may have facilitated stall use and allowed for the greater lying times observed in lame cows compared with previous work using rubber crumb mattresses without foam cushioning.

This is the first time that the effect of lameness on transition cow behavior and metabolic status has been determined. Although no relationship between lameness and NEFA was found, LMS 3 cows suffered significantly higher BHBA concentrations very soon after calving, which appeared unrelated to fat mobilization before calving. Although feeding behavior was not monitored in this study, it is possible that lameness in the early postpartum period may affect DMI at this crucial time and increase the risk for ketosis. Time budgets are often restricted in early lactation due to time spent in lock-up for fresh cow checks and other management tasks, and the 2-h difference in lying time observed in the hospital pen between LMS 3 and LMS 1 cows may have decreased the time available for feeding and put the lame cows under greater metabolic stress. Lameness has already been shown to affect feeding behavior in other studies with decreased feeding time and decreased DMI reported (González et al., 2008). In this scenario, it is interesting to speculate on the effect of decreasing milking frequency in early lactation on lame cows so that time available in the pen is less restricted. Although increased milking frequency in early lactation has been a focus of interest in recent times (Dahl et al., 2004), little work exists on the effect of decreased milking frequency during this period after calving on health and production.

Stocking density measures and time in each transition pen were not significant in any of the behavior or metabolic models. Using a similar methodology to the current study, Oetzel et al. (2007) were able to show that increasing stocking density in the close-up pen was associated with lowered 85-d milk production, and prolonged time in the maternity pen elevated risk for higher blood NEFA, BHBA, and risk for early lactation removal. High stocking rates greater than 1.2 cows per stall have been shown to decrease resting time in controlled studies (Fregonesi et al., 2007), but this level of overstocking was not reached in the current study. The 2-row pen design may have been significant in decreasing the range in variability of bunk space per cow compared with that observed in 3-row pens, due to the greater bunk length per cow provided in the 2-row layout, and although the average maternity pen stay was over $4 \mathrm{~d}$ in the study herd, bunk space was generous and the lying area comfortable to enable cattle to recover from any fat mobilization that may have started in the close-up period.

Locomotion score significantly influenced the number of lying bouts per day, particularly during the period immediately around calving time, when the cows were located in the maternity bedded pack. Interestingly, only LMS 2 and 3 cows suffered a spike in the number of bouts at this time, whereas bout number remained relatively unchanged for score 1 cows. This change in behavior observed in lame cows contrasts with the stall use behavior observed in lame cows at times other than the transition period. Both decreased number of lying bouts per day (Gomez and Cook, 2010) and increased bout duration (Chapinal et al., 2009) have been reported in lame lactating cows. Thus, the increase in the number of bouts per day observed in the lame transition cows in the current study is very significant, and it may reflect a response to the pain and discomfort of parturition. Whay et al. (1998) demonstrated that cows with sole ulcers suffered lower nociceptive thresholds for prolonged periods of time than nonlame cows. Thus, lameness may be a cause of central sensitization and winding-up of the central nervous system (Woolf, 1983) 
and the behavioral response observed is consistent with the notion that lame cows are truly hypersensitive to painful stimuli (Whay et al., 1998). Clearly care of the lame periparturient cow should be the focus of further work. The findings of this study raise questions, which relate to whether or not we should keep lame cows in freestalls within a week of expected calving, given the dramatic change in lying behavior observed, which type of bedding surface is optimal, and the potential role for analgesia to ameliorate some of the negative effects of lameness on behavior and metabolic indicators of disease.

Only 4/18 LMS1 score 1 cows at the start of the study became lame after calving. This was too small of a subgroup to compare resting behavior with the nonlame group statistically. Significant changes in LMS were observed in primiparous cows between 16 and 37 DIM, consistent with previous findings (Leach et al., 1997; Whay et al., 1997). However, the cause of this lameness was unclear as no consistent lesion was identified. The mechanism by which behavior during the transition period affects the onset of early lactation lameness warrants further investigation, but recent studies suggest that decreased rest at this critical time may be associated with the development of claw horn lesions in early or midlactation (Chapinal et al., 2009; Proudfoot et al., 2010).

\section{CONCLUSIONS}

Significant changes in resting behavior were observed during the transition period for primiparous and multiparous cows housed in a commercial freestall facility. Superimposed on behavioral alterations that can be considered a normal part of the process of parturition is an effect of lameness. Lame cows were observed to have longer lying times throughout the transition period and notably for $3 \mathrm{~d}$ before and after calving, they had a significantly greater number of lying bouts per day than nonlame cows. Lameness was also associated with a greater risk for ketosis in the study farm, as evidenced by the elevated BHBA concentration found in LMS 3 cows. Ketosis was not associated with elevated NEFA prepartum in the study herd.

\section{ACKNOWLEDGMENTS}

This study was supported by the University of Wisconsin Cow Comfort and Well-Being Consortium, which consists of Zinpro Corporation (Minneapolis, MN), Pfizer Inc. (New York, NY), Alta Genetics (Watertown, WI), Vita Plus Corporation (Madison, WI), and AgSource Cooperative Services (Verona, WI). The authors thank Rick Trinko (Rick-A-Shaw Hoof Trim- ming, Middleton, WI) for his assistance with hoof trimming and the owners and workers of the study herd for their assistance as they continue to strive to improve lameness prevention in their herd.

\section{REFERENCES}

Bergsten, C., and A. H. Herlin. 1996. Sole haemorrhages and heel horn erosion in dairy cows: The influence of housing system on their prevalence and severity. Acta Vet. Scand. 37:395-408.

Bewley, J. M., R. E. Boyce, J. Hockin, L. Munksgaard, S. D. Eicher, M. E. Einstein, and M. M. Schutz. 2010. Influence of milk yield, stage of lactation, and body condition on dairy cattle lying behaviour measured using an automated activity monitoring sensor. J. Dairy Res. 77:1-6.

Chapinal, N., A. M. de Passillé, D. M. Weary, M. A. G. von Keyserlingk, and J. Rushen. 2009. Using gait score, walking speed, and lying behavior to detect hoof lesions in dairy cows. J. Dairy Sci. 92:4365-4374.

Chaplin, S. J., H. E. Ternent, J. E. Offer, D. N. Logue, and C. H. Knight. 2000. A comparison of hoof lesions and behavior in pregnant and early lactation heifers at housing. Vet. J. 159:147-153.

Cook, N. B. 2003. Prevalence of lameness among dairy cattle in Wisconsin as a function of housing type and stall surface. J. Am. Vet. Med. Assoc. 223:1324-1328.

Cook, N. B., T. B. Bennett, and K. V. Nordlund. 2004. Effect of free stall surface on daily activity patterns in dairy cows, with relevance to lameness prevalence. J. Dairy Sci. 87:2912-2922.

Cook, N. B., M. J. Marin, R. L. Mentink, T. B. Bennett, and M. J. Schaefer. 2008. Comfort zone-design free stalls: Do they influence the stall use behavior of lame cows? J. Dairy Sci. 91:4673-4678.

Cook, N. B., R. L. Mentink, T. B. Bennett, and K. Burgi. 2007. The effect of heat stress and lameness on time budgets of lactating dairy cows. J. Dairy Sci. 90:1674-1682.

Cook, N. B., and K. V. Nordlund. 2009. The influence of the environment on dairy cow behavior, claw health and herd lameness dynamics. Vet. J. 179:360-369.

Dahl, G. E., T. L. Auchtung, and E. D. Reid. 2004. Manipulating milk production in early lactation through photoperiod changes and milking frequency. Vet. Clin. North Am. Food Anim. Pract. 20:675-685.

Duffield, T. F., K. D. Lissemore, B. W. McBride, and K. E. Leslie. 2009. Impact of hyperketonemia in early lactation dairy cows on health and production. J. Dairy Sci. 92:571-580.

Edmonson, A. J., I. J. Lean, L. D. Weaver, T. Farver, and G. Webster. 1989. A body condition scoring chart for Holstein dairy cows. J. Dairy Sci. 72:68-78.

Endres, M. I., and A. E. Barberg. 2007. Behavior of dairy cows in an alternative bedded-pack housing system. J. Dairy Sci. 90:41924200.

Espejo, L. A., M. I. Endres, and J. A. Salfer. 2006. Prevalence of lameness in high-producing Holstein cows housed in freestall barns in Minnesota. J. Dairy Sci. 89:3052-3058.

Found, K. H., H. Putnam-Dingwell, and K. E. Leslie. 2007. An investigation of the prepartum behavior of primiparous and multiparous dairy cattle. In Proc. Merck-Merial-NIH National Veterinary Scholars Symposium and AAVMC Symposium, Bethesda, MD.

Fregonesi, J. A., C. B. Tucker, and D. M. Weary. 2007. Overstocking reduces lying time in dairy cows. J. Dairy Sci. 90:3349-3354.

Gomez, A., and N. B. Cook. 2010. Time budgets of lactating dairy cattle in commercial freestall herds. J. Dairy Sci. 93:5772-5781.

González, L. A., B. J. Tolkamp, M. P. Coffey, A. Ferret, and I. Kyriazakis. 2008. Changes in feeding behavior as possible indicators for the automatic monitoring of health disorders in dairy cows. J. Dairy Sci. 91:1017-1028.

Hirst, W. M., R. D. Murray, W. R. Ward, and N. P. French. 2002. A mixed-effects time-to-event analysis of the relationship between first-lactation lameness and subsequent lameness in dairy cows in the UK. Prev. Vet. Med. 54:191-201. 
Huzzey, J. M., D. M. Veira, D. M. Weary, and M. A. G. von Keyserlingk. 2007. Prepartum behavior and dry matter intake identify dairy cows at risk for metritis. J. Dairy Sci. 90:3220-3233.

Huzzey, J. M., M. A. G. von Keyserlingk, and D. M. Weary. 2005. Changes in feeding, drinking, and standing behavior of dairy cows during the transition period. J. Dairy Sci. 88:2454-2461.

Ito, K., M. A. G. von Keyserlingk, S. J. LeBlanc, and D. M. Weary. 2010. Lying behavior as an indicator of lameness in dairy cows. J. Dairy Sci. 93:3553-3560.

Knott, L., J. F. Tarlton, H. Craft, and A. J. F. Webster. 2007. Effects of housing, parturition and diet change on the biochemistry and biomechanics of the support structures of the hoof of dairy heifers. Vet. J. 174:277-287.

Leach, K. A., D. N. Logue, S. A. Kempson, J. E. Offer, H. E. Ternent, and J. M. Randall. 1997. Claw lesions in dairy cattle: Development of sole and white line haemorrhages during the first lactation. Vet. J. $154: 215-225$

Munksgaard, L., C. G. Reenen, and R. Boyce. 2006. Automatic monitoring of lying, standing and walking behavior in dairy cattle. J. Anim. Sci. 84(Suppl.):304.

National Research Council. 2001. Nutrient Requirements of Dairy Cattle. 7th rev. ed. National Academy Press, Washington, DC.

NOAA (National Oceanic and Atmospheric Administration). 1976. Livestock hot weather stress. US Dept. Commerce, Natl. Weather Serv. Central Reg. Operations Manual Lett. C31-76. NOAA, Kansas City, MO.

Nordlund, K. V., N. B. Cook, and G. R. Oetzel. 2004. Investigation strategies for laminitis problem herds. J. Dairy Sci. 87(E. Suppl.):E27-E35.

Oetzel, G. R. 2004. Monitoring and testing dairy herds for metabolic disease. Vet. Clin. North Am. Food Anim. Pract. 20:651-674.

Oetzel, G. R., K. M. Emery, W. P. Kautz, and J. E. Nocek. 2007. Direct-fed microbial supplementation and health and performance of pre- and postpartum dairy cattle: A field trial. J. Dairy Sci. 90:2058-2068.
Proudfoot, K. L., J. M. Huzzey, and M. A. G. von Keyserlingk. 2009 The effect of dystocia on the dry matter intake and behavior of Holstein cows. J. Dairy Sci. 92:4937-4944.

Proudfoot, K. L., D. M. Weary, and M. A. G. von Keyserlingk. 2010 Behavior during transition differs for cows diagnosed with claw horn lesions in mid lactation. J. Dairy Sci. 93:3970-3978.

SAS Institute. 2009. SAS User's Guide: Statistics. Version 9.2. SAS Institute Inc., Cary, NC.

Shearer, J., D. Anderson, W. Ayars, E. Belknap, S. Berry, C. Guard, K. Hoblet, E. Hovingh, G. Kirksey, A. Langhill, A. Mills, D. Miskimins, J. Osterstock, R. Price, D. Prigel, A. Roussel, S. van Amstel, R. Wallace, J. Wasson, N. Cook, E. Garrett, D. Hostetler, and L. Shugel. 2004. A record-keeping system for capture of lameness and foot-care information in cattle. Bovine Practitioner 38:83-92.

Sogstad, A. M., T. Fjeldaas, O. Østerås, and K. Plym Forshell. 2005. Prevalence of claw lesions in Norwegian dairy cattle housed in tie stalls and free stalls. Prev. Vet. Med. 70:191-209.

Webster, A. J. F. 2001. Effects of housing and two forage diets on the development of claw horn lesions in dairy cows at first calving and in first lactation. Vet. J. 162:56-65.

Wells, S. J., A. M. Trent, W. E. Marsh, and R. A. Robinson. 1993 Prevalence and severity of lameness in lactating dairy cows in a sample of Minnesota and Wisconsin dairy herds. J. Am. Vet. Med. Assoc. 202:78-82.

Whay, H. R., A. E. Waterman, and A. J. F. Webster. 1997. Associations between locomotion, claw lesions and nociceptive threshold in dairy heifers during the peri-partum period. Vet. J. 154:155-161.

Whay, H. R., A. E. Waterman, A. J. F. Webster, and J. K. O'Brien. 1998. The influence of lesion type on the duration of hyperalgesia associated with hindlimb lameness on dairy cattle. Vet. J. $156: 23-29$

Woolf, C. J. 1983. Evidence for a central component of post-injury pain hypersensitivity. Nature 306:686-688. 